\title{
Treatment of Female Stress Urinary Incontinence with Hybrid Fractional Laser, Preliminary Study
}

\author{
Jack Pardo Schanz*, Vicente Sola Dalenz and Isabel Oporto Almiron \\ Clinica Ginestetica-Laser Rejuvenation Institute, Chile
}

Submission: August 23, 2018; Published: September 07, 2018

"Corresponding author: Jack Pardo Schanz, Clinica Ginestetica-Laser Rejuvenation Institute, Santiago, Chile, Email: drjackpardo.s@gmail.com

\begin{abstract}
Background: Stress urinary incontinence (SUI) is the involuntary loss of urine during activities requiring increased abdominal activation such as sneezing, coughing, jumping, physical exercise and sports. Despite its prevalence, SUI remains underdiagnosed and undertreated. Current lifestyle and physical therapy treatments have limited success, while surgical options carry with them the risk of significant adverse effects. In recent years, the use of the Er: YAG laser treatment has demonstrated efficacy in alleviating SUI symptoms with minimal adverse effects. A new hybrid fractional laser that enables delivery of both ablative $2940 \mathrm{~nm}$ and non-ablative $1470 \mathrm{~nm}$ wavelengths, either independently or blended, was recently introduced. This study evaluated its safety and efficacy in SUI.Aim: To determine the knowledge, attitudes and practices of postpatum women with respect to cervical cancer in the health districts of Maroua, northern Cameroon.
\end{abstract}

Methods: We enrolled 19 women with mild-to-severe SUI in this open-label, non-randomized, prospective pilot trial. Inclusion criteria were mild-to-severe SUI, the ability to complete the Consultation on Incontinence Modular Questionnaire Short Form (ICIQ-SF), and the ability to provide voluntary written consent. The degree of SUI and its impact on quality of life was assessed using the ICIQ-UI SF administered at baseline and again 3 months after treatment. Improvement was defined as an ICIQ-SF score lower than baseline regardless of severity stage. The hybrid fractional laser (diVa, Sciton Inc, Palo Alto, CA) was used with ablative $2940 \mathrm{~nm}$ and non-ablative $1470 \mathrm{~nm}$ laser wavelengths in an outpatient setting. One treatment pass delivered in 360 degrees circumference to vaginal canal and second pass to anterior vaginal wall was performed.

Result: The mean score on the ICIQ-UI at baseline was 12.7 (8-20 range). At 3 months follow-up, the ICIQ-UI mean score was 4.7 (0-14), a $68.4 \%$ improvement $(\mathrm{p}<0.05)$. Five participants $(26.3 \%)$ demonstrated a $100 \%$ improvement. One patient had a higher ICIQ SF score at 3 months and worsening of symptoms at 3 months. There were no adverse effects, pain, or discomfort reported.

Discussion: The results of this pilot study demonstrate that a single treatment with a hybrid fractional laser can improve symptoms of SUI based on the ICIQ-UI with no adverse effects. Treatment was well tolerated. We will report the results after a second treatment session.

Keywords: Pelvic floor muscle training; Midurethral sling; Tension-free vaginal tape; Retropubic; Transobturator; Single-incision mini-sling; Female Sexual Function Index

Abbreviations: SUI: Stress urinary incontinence; PFMT: Pelvic Floor Muscle Training; MUS: Midurethral Sling; TFVT: Tension-Free Vaginal Tape; RP: Retropubic; TOT: Transobturator; SIM: single-incision mini-sling; FSFI: Female Sexual Function Index; FSD: Female Sexual Dysfunction; ICIQ-SF: Consultation on Incontinence Modular Questionnaire Short Form; ICIQ: Incontinence Modular Questionnaire; ISI: Incontinence Severity Index

\section{Introduction}

Stress urinary incontinence (SUI) is the involuntary loss of urine during activities requiring increased abdominal activation such as sneezing, coughing, jumping, physical exercise and sports. It is the most common form of incontinence, accounting for approximately half of all cases. Urge incontinence accounts for $34 \%$ and mixed incontinence for $16 \%[1,2]$. Despite its prevalence, SUI remains underdiagnosed and undertreated [35].

Stress urinary incontinence typically occurs as the result of weakened pelvic floor muscles that impair the ability of the urethral sphincter to completely close, leading to urine loss at lower-than-normal abdominal pressure. The nerves that control the pelvic floor may also be damaged, while the collagen-dependent connective tissues that provide pelvic support may be weakened [6,7]. Risk factors for SUI include obesity, menopausal status, parity, vaginal delivery, pelvic floor disorders, gynecological surgery, smoking, diabetes, and physical and sexual activity [8].

The condition has a significant impact on women's quality of life, with one survey of 605 women finding that $77.5 \%$ were bothered by their symptoms; $28.8 \%$ moderately to extremely. The condition impacted their ability to participate in physical 
activities, their confidence, and their daily and social activities. Less than half of those who reported being moderately to extremely bothered $(46.6 \%)$ had ever talked with a physician about it [9].

\section{Current treatment approaches}

There are numerous therapies for SUI. Lifestyle and nonsurgical approaches weight loss, smoking cessation, behavioral therapy, pelvic floor muscle training (PFMT), vaginal devices, electrical stimulation, and biofeedback $[10,11]$.

The gold standard surgical intervention for SUI is the midurethral sling (MUS) using tension-free vaginal tape (TFVT), with a retropubic (RP)or transobturator (TOT) approach $[12,13]$. The procedure has been extensively studied and demonstrates good efficacy over the long term [14]. However, there is also a significant complication rate, including hemorrhage, bladder perforation, urethral injury, infection, and groin pain, as well as inherent risks from the anesthesia $[15,16]$. Numerous lawsuits have been filed in several countries against device manufactures and some products have been withdrawn from the market [15].

A recently published retrospective cohort study of 92,246 first-time TFVT, TOT, or RP surgical mesh procedures between April 2007 and March 2015 in England found complication rates in the unconfounded cohort (no concomitant procedures, or such procedures were unlikely to affect outcomes or were rescue procedures associated with the mesh insertion procedure) within 30 days or 5 years of $9.8 \%$. The complication rate within the potentially confounded cohort it was $12.8 \%$. The authors also reported high 30 -day readmission rates in both groups $(7.1 \%$ in unconfounded and $9.7 \%$ in confounded cohort) [15].

Another surgical option is the single-incision mini-sling (SIM). Proponents claim it offers a safer, less invasive alternative with faster recovery time, less post-operative pain, and the ability to be performed in an outpatient setting. However, while studies show similar or non-inferior short-term clinical efficacy compared to MUS, there is little long-term data $[10,17]$.

\section{Laser therapy}

A newer, non-surgical, minimally invasive option is nonablative laser treatment with Er-YAG laser, which has been used safely for more than a decade in dermatology and aesthetic medicine $[18,19]$. The photothermal effects lead to collagen remodeling and stimulates neocollagenesis, thus strengthening an important component of pelvic floor supportive structures. Indeed, biopsy studies after Er: YAG laser exposure demonstrate improvement in pelvic muscle tissue thickness and structure as well as increased vascularization, as well as SUI symptoms in pre- and postmenopausal women [7,20-22].

Several studies demonstrate improvement in SUI symptoms with Er: YAG. One of the largest involved 175 patients, $66 \%$ of whom had newly diagnosed SUI. After an average of 2.5 Er: YAG distinct laser procedures over 12 months, there was a significant improvement based on the International Consultation on
Incontinence Modular Questionnaire (ICIQ) and Incontinence Severity Index (ISI) in 77\% of participants regardless of age, with minimal discomfort or pain during the procedure reported [21].

One of the few randomized, controlled trials compared Er: YAG to Kegel exercises found a significant improvement in SUI symptoms at 6 months with the laser group with no change in the control group [22].

Analyses of 2 studies suggest that the best results of Er: YAG laser treatment would occur in younger women with a BMI $<23.3$; an average birthweight of children of $>3.6 \mathrm{~kg}$; a baseline ICIQ-UI of <10; and perineometer squeeze duration at a baseline of 3.51 seconds or higher. The authors also reported that the critical age for Er: YAG laser effect was 47.5 years $[23,24]$.

We previously reported on a longitudinal, prospective study investigating the efficacy of laser photothermal therapy in 42 women with mild-to-severe SUI after 2 sessions of non-ablative Er: YAG laser. The median ICIQ-UI score dropped from 11 at baseline to 3 at 6 months follow-up $(\mathrm{P}<0.001)$. The majority of participants (78.6\%) reported improvement and $38.1 \%$ reported complete remission of SUI at follow up. In addition, $66.7 \%$ of participants reported high satisfaction with the procedure, while $81.8 \%$ of the 33 sexually active women in the trial reported improved sexual satisfaction. The only adverse effect was mild discomfort during the procedure [25].

More recently, an innovative hybrid laser was introduced that offered another minimally invasive option. This hybrid fractional laser enables delivery of both ablative $2940 \mathrm{~nm}$ and non-ablative $1470 \mathrm{~nm}$ wavelengths, either independently or blended, which should improve tissue remodeling while keeping surrounding tissue intact and reducing healing time.

The safety and efficacy of the hybrid fractional laser was assessed in an open-label study of 20 premenopausal women (18 of whom completed the study), mean age 41 , with self-reported vaginal laxity. Twelve had SUI symptoms. Participants received 3 laser treatments performed at 4- to 6-week intervals [26].

Three domains on the Female Sexual Function Index (FSFI) were assessed: lubrication, orgasm, and dyspareunia. Eleven subjects were initially classified with female sexual dysfunction (FSD) based on the FSFI score. By 8 months, 73\% ( $n=8$ ) no longer met the FSD criteria. In addition, $80 \%$ of participants with mildto-moderate SUI ( $\mathrm{n}=9)$ demonstrated complete resolution at 1 month follow up based on the ICIQ-UI; $55 \%(n=5)$ at 8 months. Mean epithelial thickness increased with evidence of increased denser collagen, increased fibroblasts, and greater vascularity [26].

The objective of this current study was to establish the safety and efficacy of SUI treatments with a hybrid fractional laser combining ablative Er: YAG (2940nm) and non-ablative diode (1470nm) independently adjustable for depth of penetration and density of coverage in the treatment of SUI. Here, we report on the results after 1 treatment and 3 months follow up. 


\section{Methods}

This pilot, prospective study was performed between November 2017 and February 2018 in Clinica Ginestetica, a private health center in Santiago, Chile.

Inclusion criteria were mild-to-severe SUI, the ability to complete the ICIQ-UI SF, and the ability to provide voluntary written consent. Exclusion criteria were exclusive urge incontinence, severe prolapse, current pregnancy, previous surgery for SUI, severe neurological conditions, vaginal lesions, genitourinary tract infections, abnormal vaginal bleeding, history of photosensitivity disorder or use of photosensitizing drugs, and hematuria.

The degree of SUI, and its impact on quality of life was assessed using the ICIQ-UI SF administered in person by the lead investigator.

A follow-up ICIQ-SF questionnaire was administered 3 months after treatment to assess any improvement of SUI symptoms and quality of life. This assessment was performed via telephone by a non-medical employee. Improvement was defined as an ICIQ SF score lower than baseline regardless of severity stage.

Although it was not the main objective of this study, patient satisfaction with the treatment and sexual life improvement were also reported across an ordinal scale: no satisfaction, low, moderate, or high satisfaction.

The hybrid fractional laser (diVa, Sciton Inc, Palo Alto, CA) was used with ablative $2940 \mathrm{~nm}$ and non-ablative $1470 \mathrm{~nm}$ laser wavelengths. The treatment was performed using outpatient clinical settings. Topical anesthetic lidocaine was applied 20 minutes prior to the treatment procedure.

Table 1: Treatment Parameters $(n=19)$.

\begin{tabular}{|c|c|c|c|c|c|}
\hline & Passes & \multicolumn{2}{|c|}{$1470 \mathrm{~nm}$} & \multicolumn{2}{c|}{ 2940nm } \\
\hline & & $\begin{array}{c}\text { Depth } \\
(\boldsymbol{\mu m})\end{array}$ & $\begin{array}{c}\text { Density } \\
(\%)\end{array}$ & $\begin{array}{c}\text { Depth } \\
(\boldsymbol{\mu m})\end{array}$ & $\begin{array}{c}\text { Density } \\
(\%)\end{array}$ \\
\hline $\begin{array}{c}\text { Pre- } \\
\text { menopausal }\end{array}$ & 2 & 500 & 6 & 300 & 7 \\
\hline $\begin{array}{c}\text { Post- } \\
\text { menopausal }\end{array}$ & 2 & 400 & 4 & 200 & 7 \\
\hline
\end{tabular}

Treatment settings for pre-menopausal and postmenopausal subjects are shown in Table 1. Settings for pre-menopausal participants were $1470 \mathrm{~nm}-500 \mathrm{um}$ depth (6\% density) and $2940 \mathrm{~nm}$ - 300um depth (7\% density). Treatment settings for post-menopausal participants were $1470 \mathrm{~nm}-400 \mathrm{um}$ depth $(4 \%$ density), 2940nm-200um depth (7\% density). One treatment pass delivered in 360 degrees circumference to vaginal canal and another pass was delivered to the anterior vaginal wall. The results after the initial treatment are reported here (Table 1).

\section{Statistical analysis}

Student t-test was used for statistical analysis.

\section{Result}

Nineteen female participants were enrolled with a median age of 47.4 years (32-64). Fifteen women had at least 1 vaginal delivery; 3 had at least 1 cesarean delivery; and 1 participant had not delivered any children. Ten participants were premenopausal and 9 were post-menopausal.

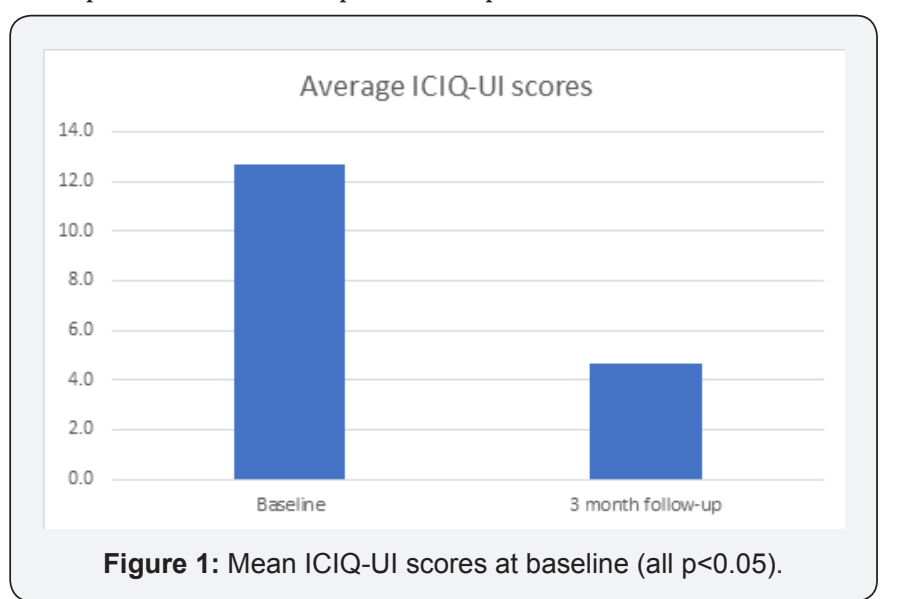

The mean score on the ICIQ-UI at baseline was 12.7 (8-20 range) (Figure 1). Ten participants (52.6\%) also demonstrated urge incontinence. At 3 months follow-up, the ICIQ-UI mean score was $4.7(0-14)$, a $68.4 \%$ improvement. Five participants (26.3\%) demonstrated a $100 \%$ improvement. One patient had a higher ICIQ-UI SF score at 3 months and worsening of symptoms at 3 months.

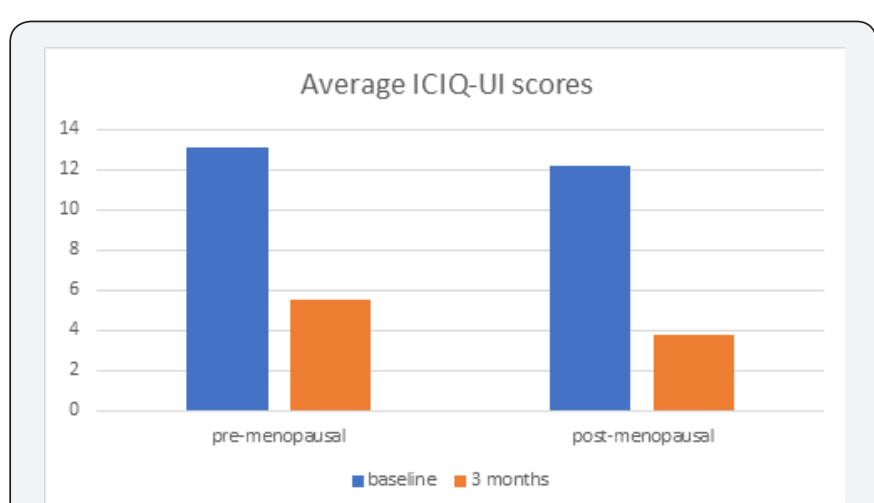

Figure 2: Mean ICIQ-UI scores at baseline and 3 months after first treatment based on menopausal status $(p<0.05)$.

Figure 2 depicts the mean scores at baseline and follow up based on menopausal status. Pre-menopausal women experienced a $58 \%$ improvement and post-menopausal women a $69 \%$ improvement (all $\mathrm{P}<0.05$ ).

There were no adverse effects, pain, or discomfort reported. The procedure itself took between 10 and 15 minutes. Eighteen of the 19 participants (94.7\%) subjectively reported an improvement. Although not a study objective, $80 \%(n=12)$ of the 15 women who were sexually active reported improved sexual satisfaction. Of the 19 patients, $17(89.5 \%)$ said they would repeat the treatment and recommend it to others. 


\section{Discussion}

The results of this study demonstrate that a single treatment with a hybrid fractional laser can improve symptoms of SUI based on the ICIQ-UI with no adverse effects. Treatment was well tolerated by all subjects.

This study demonstrated $94.7 \%$ subjectively satisfied improvement in SUI after just 1 treatment session. An earlier study from Pardo et al on the efficacy of 2 sessions with a nonablative Er: YAG laser in 42 women with mild-to-severe SUI demonstrated a 79\% improvement. Both studies reported improved sexual satisfaction [25].

This study is, to the author's knowledge, the first to evaluate a hybrid fractional laser in the treatment of SUI only. An earlier, open-label study of a similar device that included 12 pre-menopausal women with vaginal laxity and SUI also demonstrated a reduction in ICIQ-UI SF scores in 9 participants with mild-to-moderate SUI [26].

Limitations of this study include the lack of a control group; the fact that this was an open label study; the small study population; and the short follow-up time.

\section{Conclusion}

A single treatment with a hybrid fractional laser in pre and post-menopausal women appears to provide a quick, safe outpatient procedure for the treatment SUI, with a significant reduction in SUI symptoms. This minimally invasive procedure is comfortable and results in minimal to no bleeding or other adverse effects seen with surgical interventions for SUI. Larger, controlled trials will be needed to validate the findings of this study.

\section{References}

1. Dooley Y, Kenton K, Cao G, Luke A, Durazo-Arvizu R et al. (2008) Urinary incontinence prevalence: results from the National Health and Nutrition Examination Survey. J Urol 179(2): 656-661.

2. Reynolds WS, Dmochowski RR, Penson DF (2011) Epidemiology of stress urinary incontinence in women. Curr Urol Rep 12(5): 370-376.

3. Wallner LP, Porten S, Meenan RT, O’Keefe Rosetti MC, Calhoun EA, et al. (2009) Prevalence And Severity Of Undiagnosed Urinary Incontinence In Women. The American journal of medicine 122(11): 1037-1042.

4. Kinchen KS, Burgio K, Diokno AC, Fultz NH, Bump R, et al. (2003) Factors associated with women's decisions to seek treatment for urinary incontinence. J Womens Health (Larchmt) 12(7): 687-698.

5. Melville JL, Newton K, Fan MY, Katon W (2006) Health care discussions and treatment for urinary incontinence in U.S. women. Am J Obstet Gynecol 194(3): 729-737.

6. Cervigni M, Gambacciani M (2015) Female urinary stress incontinence. Climacteric 18 Suppl 1: 30-36.

7. Conte C, Jauffret T, Vieillefosse S, Hermieu JF, Deffieux X (2017) Laser procedure for female urinary stress incontinence: A review of the literature. Prog Urol 27(17): 1076-1083.

8. Perera J, Kirthinanda DS, Wijeratne S, Wickramarachchi TK (2014) Descriptive cross sectional study on prevalence, perceptions, predisposing factors and health seeking behaviour of women with stress urinary incontinence. BMC Womens Health 14: 78.
9. Fultz NH, Burgio K, Diokno AC, Kinchen KS, Obenchain R, et al. (2003) Burden of stress urinary incontinence for community-dwelling women. Am J Obstet Gynecol 189(5): 1275-1282.

10. Shamout S, Campeau L (2017) Stress urinary incontinence in women: Current and emerging therapeutic options. Can Urol Assoc J 11(6 Suppl 2): S155-S158.

11. ACOG Practice Bulletin No. 155: Urinary Incontinence in Women. Obstet Gynecol. 2015;126(5):e66-81.

12. Hermieu JF, Conquy S, Leriche B, Debodinance P, Delorme E, et al. (2010) Synthèse des recommandations pour le traitement de l'incontinence urinaire féminine non neurologique. Prog Urol 20 Suppl: S94-S99.

13. Chapple CR, Cruz F, Deffieux X, Milani AL, Arlandis S, et al. (2017) Consensus Statement of the European Urology Association and the European Urogynaecological Association on the Use of Implanted Materials for Treating Pelvic Organ Prolapse and Stress Urinary Incontinence. Eur Urol 72(3): 424-431.

14. Ford AA, Rogerson L, Cody JD, Aluko P, Ogah JA (2017) Mid-urethral sling operations for stress urinary incontinence in women. Cochrane Database Syst Rev 7: Cd006375.

15. Keltie K, Elneil S, Monga A, Hannah Patrick, John Powell, et al. (2017) Complications following vaginal mesh procedures for stress urinary incontinence: an 8 year study of 92,246 women. Sci Rep 7(1):12015.

16. Kobashi KC, Albo ME, Dmochowski RR, Ginsberg DA, Goldman HB (2017) Surgical treatment of female stress urinary incontinence: AUA/ SUFU guideline. J Urol 198(4): 875-883.

17. Nambiar A, Cody JD, Jeffery ST, Aluko P (2017) Single-incision sling operations for urinary incontinence in women. Cochrane Database Syst Rev 7: Cd008709.

18. Bodendorf MO, Willenberg A, Anderegg U, Grunewald S, Simon JC, et al. (2010) Connective tissue response to fractionated thermo-ablative Erbium: YAG skin laser treatment. Int J Cosmet Sci 32(6): 435-445.

19. Wood VT, Pinfildi CE, Neves MA, Parizoto NA, Hochman B, et al. (2010) Collagen changes and realignment induced by low-level laser therapy and low-intensity ultrasound in the calcaneal tendon. Lasers Surg Med 42(6): 559-565.

20. Fistonic N, Fistonic I, Gustek SF, Turina IS, Marton I, et al. (2016) Minimally invasive, non-ablative Er:YAG laser treatment of stress urinary incontinence in women--a pilot study. Lasers Med Sci 31(4): 635-643.

21. Ogrinc UB, Sencar S, Lenasi H (2015) Novel minimally invasive laser treatment of urinary incontinence in women. Lasers Surg Med 47(9): 689-697.

22. Fistonic I (2013) Laser Treatment for Early Stages of Stress Urinary Incontinence and Pelvic Muscle Relaxation Syndrome. J Laser Health Acad 2013(1): S26.

23. Fistonic I, Fistonic N (2018) Baseline ICIQ-UI score, body mass index, age, average birth weight, and perineometry duration as promising predictors of the short-term efficacy of Er:YAG laser treatment in stress urinary incontinent women: A prospective cohort study. Lasers Surg Med.

24. Fistonic N, Fistonic I, Lukanovic A, Findri Gustek S, Sorta Bilajac Turina I, et al. (2015) First assessment of short-term efficacy of Er:YAG laser treatment on stress urinary incontinence in women: prospective cohort study. Climacteric 18 Suppl 1: 37-42.

25. Pardo JI, Sola VR, Morales AA (2016) Treatment of female stress urinary incontinence with Erbium-YAG laser in non-ablative mode. Eur J Obstet Gynecol Reprod Biol 204: 1-4.

26. Peet JJ, Evaluation of the Safety and Efficacy of Hybrid Fractional $2940 \mathrm{~nm}$ and 1470nm Lasers for Treatment of Vaginal Tissue: Pilot Study. Sciton. 
This work is licensed under Creative Commons Attribution 4.0 License

DOI:10.19080/JGWH.2018.11.555815

\section{Your next submission with Juniper Publishers} will reach you the below assets

- Quality Editorial service

- Swift Peer Review

- Reprints availability

- E-prints Service

- Manuscript Podcast for convenient understanding

- Global attainment for your research

- Manuscript accessibility in different formats

( Pdf, E-pub, Full Text, Audio)

- Unceasing customer service

Track the below URL for one-step submission https://juniperpublishers.com/online-submission.php 